126 | Japanese Language and Literature

\title{
Interactional Competence in Japanese as an Additional Language
}

Edited by Tim Greer, Midori Ishida, and Yumiko Tateyama. Honolulu: National Foreign Language Resource Center, 2017. iv, 450 pp. $\$ 30.00$.

\section{Reviewed by Joy Maa}

This edited volume comprises a collection of studies applying conversation analysis to examine the interactional competences of first and second language speakers of Japanese. The volume begins with a very brief introduction to conversation analysis and the construct of interactional competence in chapter 1 , and the remainder of the volume is devoted to eleven empirical studies that are divided into two sections: interactional competence across social activities, and developing interactional competence. As their titles suggest, the first section (chapters 2-8) concerns the interactional competences displayed by learners in a range of social settings, whereas the second section (chapters 9-12) showcases studies that adopt a longitudinal approach and trace how speakers' interactional competences change across a larger timeframe.

Starting with chapter 2, the author Burch looks at how self-deprecation is employed and accomplished in second language (L2) Japanese. The researcher analyzes conversations between a first language (L1) Chinese expatriate and her L1 Japanese friend, focusing on instances of negative self-assessments initiated by the L1 Chinese speaker regarding her own Japanese ability. In doing so, Burch reveals the sequential, categorical (i. e., invocating a certain identity), and embodied resources (e. g., facial expressions) that are employed to manage preference and dispreference as these relate to the interactional organization of self-deprecation.

In chapter 3, the author Moody investigates how learners identify and utilize opportunities to learn technical terms within the workplace. Through a combination of field notes and audio recordings, the researcher shows how two Americans interning in a Japanese engineering firm display orientation to language learning to different degrees, even as they balance the need to work on the institutional tasks at hand. Moreover, the conditions for language learning opportunities as these are leveraged and interactively managed within social activities are shown to be contingent 
upon the resources available for the given interaction, such as the interlocutor, physical objects, and contextualization.

In chapter 4, the author Bushnell addresses the sequential organization of laughter among L2 Japanese university students at a rakugo performance. In his analysis, he examines the manner in which the performer and audience members co-accomplish laughter at certain positions, and also the competencies-linguistic, pragmatic and interactional-underlying laughter produced at different times. Specifically, the researcher considers how different instances of laughter may be attributed to a general understanding of the story, characters, and situation, versus comprehension of micro-level cues (i. e., linguistic, verbal, and embodied resources).

In chapter 5, Yamamoto and Yanagimachi investigate how L2 speakers co-construct their interactional competence as interviewers through recipient responses. The study follows a university L2 Japanese learner on a visit to a laboratory to interview a native Japanese speaker specializing in natural science research. Through a detailed examination of the production, formulation, and sequential positioning of recipient responses (e. g., repetition, change of state tokens, rephrasing) in one interview, the authors demonstrate the learner's ability to pay attention to interlocutor cues and to respond in a way that is projected by the interviewee, such that the responses are both facilitated and realized via the joint participation of both parties.

In chapter 6, Ikeda and Bysouth propose the notion of "multimodal interactional competence" as one aspect of interactional competence in their study on technology use in a foreign language classroom (142). In this study, the researchers consider how L2 learners manage group interaction in three different settings, in which an iPad, PC, and smart board respectively are used. Learners are shown to employ verbal and nonverbal moves to establish joint attention or action related to the technological tool present. Furthermore, they engage in different interactional practices in which technology is embedded to manage ongoing interactions, which include achieving collaborative intersubjectivity and next-speaker selection.

In chapter 7, Hasegawa explores pair work in the L2 classroom to determine how searches for what-to-say are accomplished by L2 Japanese learners in interaction. Using video recordings, the researcher identifies middle-distance gazing and speech perturbations as common characteristics of word and conjugation searches. Additionally, he analyzes how learners may resort to linguistic, interactional and embodied 
128 | Japanese Language and Literature

resources (e. g., smiles and gaze) to signal word searches and/or to invite assistance from peers.

In chapter 8, Tominaga adopts an interactional competence perspective to evaluate the adequacy of Oral Proficiency Interview (OPI) criteria. The researcher presents OPI excerpts of narration tasks by two test candidates (rated intermediate), and demonstrates how these narratives are interactionally co-constructed between the candidates and test interviewer through such resources as rising intonation and requestresponse sequences. Although the findings generally support the appropriateness of OPI guidelines, Tominaga questions the relevance of the text type rating criterion (i.e., descriptors of sentences and paragraphs), while arguing for the need for intermediate-level test guidelines to reflect the interactional competences of candidates.

In chapter 9, the author Ishida documents the development of one learner's use of receipt forms over the course of a year studying abroad, focusing on the features of interaction that contribute to opportunities for learning. The researcher analyzes several conversations between the learner and native Japanese speakers, and reveals how sequential positioning of receipts — namely, an “interlocutor's receipting actions in a particular sequence position, [their] next-turn display of understanding, and...non-orientation to inapposite use of receipt forms"-comprise clues that the learner may utilize to assist their understanding of the interactional functions of receipts (269).

In chapter 10, Mori and Matsunaga look at how an L2 Japanese learner living in foreign language housing at an American university acquires the ability to manage topics during dinnertime conversations by exercising available interactional competence. The researchers inspect excerpts collected at two points in time, illustrating the learner's attending to prior talk and use of L1, L2, and non-linguistic resources to initiate and expand upon topics in ongoing interactions. This exercise of interactional competence, in turn, generates opportunities for the learner to "create spaces for L2 learning specific to his own purpose," a process which the researchers describe as "L2 use and learning in and as interaction" (323).

In chapter 11, Tateyama documents changes in the interactional competence of a novice L2 Japanese teacher within the classroom. Specifically, she investigates the sequential environment where the formulaic expression daijobu desu ka (are you all right?) is deployed, and the social actions accomplished by this expression. By considering the instructor's non-verbal and verbal actions - including the use of semiotic resources and turn allocation-she identifies two functions of the 
expression: closing activities and checking understanding. Over time, Tateyama observes a decline in the use of daijōbu desu ka, as well as the increased use of an alternative expression ii desu ka (are you okay?) as a resource to transition between student and teacher-centered classroom activities.

The volume concludes with chapter 12, in which Greer follows recipient and turn design in conversations between L1 and L2 speakers during successive haircuts at a salon. He focuses primarily on the L1 speakers (i. e., the hairdressers) and their greetings of both L1 and L2 customers. Changes in the speakers' verbal and embodied exchanges over time (e. g., increased verbal ellipsis and use of sentence-final particles and plain form), are put forward as evidence of both emerging familiarity and developing interactional competence on the part of the L1 speakers, who adapt their use of interactional resources to their L2 (i. e., novice) interlocutors in constructing greeting sequences.

The first major strength of this volume is its coverage of a variety of settings, participants, and empirical foci. The studies address not only more traditional contexts of L2 learning, such as foreign language and L2 classrooms (chapter 6 and 7), but also the workplace (chapter 3), foreign language housing (chapter 10), service encounters (chapter 12), casual conversations (chapter 2), and entertainment (chapter 4). Study participants range from university students, both at home (chapter 7 and 10) and abroad (chapter 4 and 9), to a novice teacher (chapter 11), to native speakers (chapter 12), and to an expatriate married to a Japanese (chapter 2 ). Diversity can also be found in the interactional practices examined, which include self-deprecation (chapter 2), laughter (chapter 4), recipient responses (chapter 5 and 9), searches for what-to-say (chapter 7), narration (chapter 8), and topic management (chapter 10), among others.

The second noteworthy contribution of this volume is the timely and fresh perspective it offers on Japanese learning and research, which stresses the need to consider interactional competence-competence that is co-constructed between interlocutors - as a part of L2 Japanese acquisition. This view is in contrast to more traditional understandings of communicative competence, which have treated language proficiency as something internal to the individual learner, to be studied and assessed in isolation. Furthermore, this approach recognizes the diverse resources (e. g., L1 and L2, verbal and embodied) that learners bring to their learning and use of Japanese, as well as their potential ability to leverage these resources to communicate and accomplish actions in a given situation. At 
130 | Japanese Language and Literature

the same time, it makes clear the contingencies that are involved in the exercise of interactional competences.

Considering the use of terminology early on in the introduction, it is evident that the volume was written for those familiar with interactional competence and conversation analysis. For this reason, the volume might constitute a steep entry for those with little background in either area. In addition, it should be noted that the rationale behind the volume derives from a core assumption of conversation analysis: the "inherent universality of talk" (3). Hence, the focus is not so much on how L2 learners of Japanese acquire interactional practices unique to the language, as it is on how universal interactional practices (e. g., turn-taking and sequencing) are drawn upon, displayed, and achieved through a range of resources by L1 and L2 speakers of Japanese. Hence, the work would be of greatest relevance to those interested in how conversation analysis and a micro-interactional framework may be extended to an environment where Japanese is the primary medium of verbal communication.

One of the main limitations of this volume is the limited space devoted to teaching implications. Although some studies mention the importance of applying a perspective informed by interactional competence to the teaching of Japanese as a foreign language, there are generally few concrete suggestions as to how findings might be used to further pedagogical practices. Similarly, while the studies that are included under developing interactional competence provide snapshots of displays of interactional competence at different points in time, there is limited discussion of the causes or possible triggers for development (i. e., microgenesis). As an instructor, it would have been desirable to see more proposals for how to equip learners with resources they can leverage in constructing their interactional competence, or how to create conditions conducive to the development of interactional competence. On another note, the volume lacks a concluding chapter or word; the inclusion of even a brief summary with a "takeaway message" would have helped to bring all the studies together in a more cohesive manner.

Nevertheless, Interactional Competence in Japanese as an Additional Language represents a significant contribution to work in Japanese language and linguistics, and constitutes an informative and compelling resource for researchers and instructors interested in the micro-insights afforded by conversational analysis and who are seeking a new perspective on the learning of L2 Japanese. 